\title{
AS TEORIAS DA CONSPIRAÇÃO COMO ESPELHO DO SÉCULO: ENTRE A RETÓRICA, A SOCIOLOGIA E A HISTÓRIA DAS IDEIAS'
}

Resumo: Este artigo propõe um novo olhar, mais realista e menos político, sobre as teorias da conspiração. Desconstruindo certos mitos, ele convida a um questionamento tanto da modernidade como de nossa racionalidade à luz dessas teorias. Trata-se de analisar, sem pretensões ou falsa modéstia, as lógicas próprias do discurso conspiratório, de enfatizar seus limites, destacar nele o impensável em termos de razão moderna e de suas exigências. Segue-se daí que o objetivo do artigo é esclarecer o papel e as funções que esse tipo de discurso preenche no seio do espaço social e político. O percurso realizado provavelmente auxiliará a criar ferramentas úteis tanto para compreender essas produções do espírito - cuja força de persuasão não é negligenciável - quanto para responder a elas. Pelo menos, este é nosso desafio.

Palavras-chave: Teorias da conspiração. Crenças. Evidência. Racionalidade. Narrativa.

\begin{abstract}
This article takes a fresh look at conspiracy theories, in a more realistic and less political way. It deconstructs certain myths and invites us to question our modernity as much as our rationality in the light of these theories. Without pretense or false modesty, the article proposes to analyze the logical context of conspiracy theory discourses, to emphasize their limits, and to highlight what is not thought in our modern rationality. Based on this, the goal is to elucidate the role and functions that this type of speech fills in the social and political space. The path we take helps us to forge the tools to understand these products of mind - whose power of persuasion is not negligible - as much as to answer them. At least, that is our challenge.
\end{abstract}

Keywords: Conspiracy theories. Beliefs. Evidence. Rationality. Narrative.

\footnotetext{
'A Revista EID\&A agradece vivamente a Ferri Briquet, diretor da Presses Universitaires de Nancy, pela autorização da publicação desta tradução do original: NICOLAS, Loïc. Les théories du complot comme miroir du siècle. Entre rhétorique, sociologie et histoire des idées. Questions de communication, Nancy, n. 29, 2016. Disponível em: http://questionsdecommunication.revues.org/10380.

ii Doutor em Línguas e Letras pela Université Libre de Bruxelles (ULB), Bélgica. Pesquisador na mesma instituição e membro do Groupe de Recherche en Rhétorique et en Argumentation Linguistique (GRAL/ULB) e do Grupo de Pesquisa Estudos de Linguagem, Argumentação e Discurso (ELAD/UESC/CNPq).E-mail: Loic.Nicolas@ulb.ac.be.
} 
EID\&A - Revista Eletrônica de Estudos Integrados em Discurso e Argumentação, Ilhéus, n. 12, jul/dez.2016.

\section{Introdução}

O estudo daquilo que se nomeia "teorias da conspiração", "conspiracionismo", "pensamento conspiratório", ou ainda "teoria do complô" (a lista não é exaustiva) pode ser realizado a partir de numerosas disciplinas (ciência política, história, psicologia, sociologia, etc.) e testemunhar ambições igualmente grandes ${ }^{1}$. Pode-se tratar de descrever o fenômeno para mostrar sua atualidade impressionante, para fazer sua etiologia (estabelecer suas causas, esclarecer suas origens, identificar suas fontes), esclarecer sua evolução numa duração longa ou, como é o caso mais frequente, denunciar a vasta produção de atores no campo, tanto sob o plano lógico-racional como sob o plano político. Denúncia cujo objetivo é exibir, de formas diversas, tanto a perversidade, a irracionalidade ou o perigo das teses e dos raciocínios conspiracionistas (em termos de suas possíveis consequências), como a paranoia e até a loucura furiosa de seus produtores, e ainda a ingenuidade dos adeptos, quer dizer, seguindo o termo de Gérald Bronner (2013), dos “crentes". No entanto, enquanto a motivação política (cuja legitimidade, aliás, não se trata aqui de negar) prevalece sobre qualquer outra, a denúncia corre o risco de se exercer em detrimento de uma compreensão mais profunda das funções daquilo que é objeto de crença e de adesão, em detrimento do sentido e mesmo dos sentidos de que as ideias conspiracionistas se revestem aos olhos daqueles que as abraçam e as defendem, em detrimento do testemunho dado por essas ideias quanto ao estado, às tendências e aos fundamentos das sociedades contemporâneas.

Afinal, sabemos que aqueles que se dizem "crentes" - em comparação com os "não-crentes" - geralmente estão mais abertos a consagrar tempo, energia e meios financeiros para defender, justificar e reforçar suas crenças (ANGENOT, 2014, p. 100ss; BRONNER, 2003). Isso ocorre porque essas crenças fazem parte de sua "identidade" (BRONNER, 2013, p. 76) e assumem o lugar, mais ou menos, de um sacerdócio. Dito isso, de um ponto de vista psicocognitivo, tratando-se de teorias conspiracionistas ou não (de astronomia, de botânica, de palavrascruzadas, pouco importa), quanto mais nos apegamos a uma atividade, a uma ideia ou a um problema, mais vivemos com ele, mais temos a tendência de aumentar o tempo e o esforço que julgamos legítimo lhe consagrar (KILPATRICK, 1951). Então, o aumento contínuo do volume de um e de outro vem reforçar incessantemente o valor e a dignidade daquilo para que escolhemos atribuir -

\footnotetext{
${ }^{1}$ Agradeço a Gérald Bronner, Olivier Dard, Jean-Bruno Renard e Aurore Van de Winkel pela leitura atenta e pelas observações pertinentes que formularam a respeito de meu texto.
} 
EID\&A - Revista Eletrônica de Estudos Integrados em Discurso e Argumentação, Ilhéus, n. 12, jul/dez.2016.

ainda e sempre - mais tempo e energia. Segue-se então um efeito potencial de entusiasmo que pode se revelar difícil de conter, principalmente quando a atividade, a ideia ou o problema estrutura firmemente a visão de mundo daquele que tem compromisso com a ação, a reflexão, a pesquisa, enquanto relação com outros - em termos de socialidade e sociabilidade. Com efeito, o custo cognitivo e psicológico ligado àquele tipo de atividade, à renúncia da ideia, ao abandono do problema é tanto maior quanto o tempo que se consagrou a ela, já que uma grande parte da identidade do sujeito depende da proteção das estruturas, usos e práticas no interior do qual ela se socializou.

Em suma, quanto mais tempo passamos diante da tela do computador pesquisando, dissecando, interpretando índices e sinais suscetíveis de corroborar o quadro explicativo no seio do qual a crença num complô se forma, mais estamos inclinados a querer continuar a pesquisa daquilo que não pode estar ausente lá, mais o esforço de interpretação faz sentido, mais nos envolvemos ardosamente com a tarefa, mais sentimos como legítima a posição de investigador. Além de tudo, como escreveu ainda Gérald Bronner (2009, p. 260), quando alguém começa "a buscar sinais, eles acabam sempre aparecendo". De fato, quando há motivação, não é difícil encontrar na massa colossal de informações disponíveis, sobretudo em tempos de internet e de redes sociais, aquelas que permitirão confirmar, segundo certo ângulo de visão ou em função de uma certa associação de ideias, que existe mesmo um complô, ou colocar em dúvida as teses que alguns afirmam ser "oficiais".

$\mathrm{Na}$ contracorrente da vulgata atual, que leva a perpetuar oposições estéreis, este artigo de síntese visa a lançar luz sobre certas relações (impensadas ou mal pensadas) entre práticas discursivas e representações do mundo; entre racionalidade moderna e conspiracionismo; entre negação do acaso e concepção de narrativa. A partir daí, depois de haver convidado o leitor a enterrar as respostas simplistas, lembrando os elementos definidores da abordagem conspiracionista, irei me ater a mostrar que a acusação de irracionalidade dirigida a ela constitui um impasse. Trata-se então de articular, de um lado, efeito de evidência, imunidade e status ambíguo da argumentação; de outro lado, idealização da transparência e ilusão quanto ao caráter previsível de um mundo puro e sem asperezas. Terminarei com uma série de observações referentes às relações (perversas, pois não assumidas) da modernidade em relação ao mito e sua prática social. 
EID\&A - Revista Eletrônica de Estudos Integrados em Discurso e Argumentação, Ilhéus, n. 12, jul/dez.2016.

\section{Um arsenal não encontrável}

Não neguemos, em face da motivação, da criatividade transbordante, até desenfreada, e da determinação dos "crentes" e dos produtores de crenças conspiracionistas, o bom senso, a razão e a paciência daqueles que não creem e se encontram submetidos à pressão. $O$ cético e o cidadão desejoso de refutar as crenças em questão dizem, então, que gostariam de dispor de um arsenal de argumentos e réplicas afiadas para reduzir ao silêncio os amadores de intrigas conspiracionistas, expor-Ihes de uma vez por todas a superficialidade, a extravagância e o absurdo de suas teorias irritantes. Mas como pode ser visto, sem cinismo, tal esperança é vã. De fato, queiramos ou não, lamentemos, não poderia existir nas sociedades abertas e, mais amplamente, na democracia, qualquer receita milagrosa, qualquer frase pronta, qualquer palavra mágica, qualquer razão última capaz de desembaraçar o espaço social das ideias que irritam ou causam desgosto; capaz de proteger de línguas tolas e das tentativas de manipulação vindas de não se sabe onde.

Isso não quer dizer que não haja nada a fazer, nem nada a esperar em matéria de discurso, mas sim que a resposta para se opor aos conspiracionistas de todos os tipos não pode desprezar a complexidade nem o estatuto ambíguo das explicações que eles produzem e/ou alternam, concedendo-lhes, ao menos, certo crédito, considerando, afinal, que veicular ideias, teorias, lendas, falsidades ouvidas em qualquer lugar não significa que se adira a elas. No que se refere à questão, se essas explicações não fossem persuasivas e permanecessem sem exercer efeito sobre ninguém, nós a relegaríamos a uma classe de curiosidades e de fabulações. Se ninguém encontrasse sentido nem interesse (cognitivo, afetivo, social) em aderir a elas, em crer nelas (no todo ou em parte, com mais ou menos entusiasmo e convicção), o fenômeno não teria a amplitude que conhecemos hoje.

Em todo caso, e ainda que o mundo do contra que elas pretendem desvendar tenha algo que aterrorize seus adeptos, os esquemas de compreensão que essas explicações formulam sobre o mundo e seus dramas (guerras, revoluções, fome, epidemias, catástrofes climáticas etc.) asseguram uma tripla função de reencantamento e de satisfação cognitiva. De início, elas confortam o ego dos "crentes", rejeitando a responsabilidade de uma infelicidade ou de uma crise qualquer relativa a um inimigo (singular ou plural) que tem a reputação de injusto, cruel e, ainda mais, perverso: um inimigo mascarado cujos contornos se revelam suficientemente flexíveis e fluidos para 
EID\&A - Revista Eletrônica de Estudos Integrados em Discurso e Argumentação, Ilhéus, n. 12, jul/dez.2016.

dar asas à imaginação. Além disso, elas tranquilizam o espírito estabilizando a relação de sentido, depois confirmando, contra a hipocrisia e as tramas supostas pelos conspiradores, a existência de uma ordem justa e moral, aquela do verdadeiro mundo das pessoas verdadeiras. Enfim, a lucidez que essas explicações afirmam transmitir a seus adeptos oferece a eles a ocasião gratificante e sempre renovada de se distinguir daqueles que não viram ou que, cegados, não podem ver nem aceitar a realidade do complô.

De resto, se a denúncia das explicações conspiracionistas fosse tão fácil que se sentisse prazer em nelas crer ingenuamente, se o absurdo delas fosse evidente aos olhos de todos, poderíamos nos contentar rindo. Ora, essas teorias servem pouco ao riso porque elas expressam uma eficácia temível. É essa eficácia, suas causas, suas razões, que se deve interrogar sem fingimento e sem hipocrisia. Pois, a liberdade exige, mesmo que isso não aconteça sem riscos, mesmo que nossos ouvidos possam ser agredidos, nossas representações (sociais, morais, políticas) e nossos sentidos perturbados, as teorias da conspiração têm o direito de existir na arena política, o direito de ocupar, elas também, um lugar no seio do mercado heterogêneo de crenças e de ideologias de todo gênero. Além disso, Guy Haarscher (2007, p. 67) lembra que, "numa sociedade livre e democrática", devese aceitar que os indivíduos possam "se associar para defender por vezes as ideias mais tolas, ou para utilizar a linguagem de modo desenvolto ou sofisticadamente manipulado. Ninguém [ele acrescenta] gostaria de uma polícia do pensamento que tivesse por tarefa censurar a linguagem distorcida e corrompida", aquela dos conspiracionistas e de outros.

Em tempos de Dieudonné ${ }^{2}$, Soral ${ }^{3}$ e consortes, é importante refletir sobre isso. Cuidamos de não entrar em pânico, criando leis ou condenando a torto e a direito, e reconhecemos o quanto a censura, arma eclesiástica e braço armado do "politicamente correto" (HUGHES, 1993), tem por consequência atiçar a curiosidade e alimentar um interesse desmedido e (às vezes? sempre?) insano em relação àqueles que transgridem as proibições, os tabus e os limites. Pior, essa censura dá argumento aos transgressores profissionais, aos adversários da democracia, aos ideólogos, para reivindicar, aos gritos de anátema e de demonização, o estatuto de vítima que não Ihes é devido. Não se trata de

\footnotetext{
${ }^{2}$ NT: Dieudonné M'bala M'bala, geralmente conhecido por seu nome artístico Dieudonné, é um comediante francês, ator e ativista político. Seu pai é de Camarões e sua mãe, da França. Fonte: http://www.dieudosphere.com/; https://www.facebook.com/dieudonneofficiel/

${ }^{3}$ NT: Alain Soral, cujo nome real é Alain Bonnet, é um autor, jornalista, ensaísta e produtor de filmes franco-suíço. Fonte: https://www.facebook.com/soralrepond/
} 
EID\&A - Revista Eletrônica de Estudos Integrados em Discurso e Argumentação, Ilhéus, n. 12, jul/dez.2016.

complacência em relação a eles, mas de lucidez diante do remédio menos amargo. Um remédio que, pelo contrário, não ajuda a forjar instrumentos pessoais para se defender daquilo que com justa razão reprovamos, nem para combater discursivamente. Um remédio a partir do qual, enfim, prosperam as escleroses de uma "cultura do medo" (CRÉPON, p. 2008).

Em suma, enquanto o Estado e as mídias tomam o lugar dos indivíduos colocando limites ao que se pode pensar, ao que se pode dizer e ao verossímil, enquanto eles amaldiçoam aqueles que denunciam tais fronteiras, tachandoos de criminosos, eles fragilizam aqueles mesmos que afirmam querer proteger (NICOLAS, 2015a). De um lado, eles dispensam esses últimos de responder no espaço político, ou seja, de buscar e desenvolver uma argumentação ad hoc. De outro lado, eles dão aos admiradores dos autoproclamados "dissidentes" ${ }^{4}$ a ocasião fácil de defender e corroborar sua posição questionando apenas a repressão política e judiciária (julgada insuportável), que se torna objeto da questão. O que fragiliza uns acaba por fortalecer outros.

Por conseguinte, o enfoque defendido aqui - que se inscreve na continuidade dos trabalhos que realizo desde 2009 sobre, em torno de e a partir desse fenômeno social e linguageiro - registra esta realidade e recusa as reduções e simplificações abusivas (DANBLON \& NICOLAS, 2010, 2012; NICOLAS, 2010, 2014, 2015a, 2015b, 2015c). O objetivo é, sobretudo, chamar a atenção sobre a própria matéria discursiva (a saber, menos ao que é dito sobre essas conspirações supostas, mais ao modo como isso é dito), a fim de compreender o extraordinário potencial de persuasão das explicações conspiracionistas e os elos que elas podem manter com a razão moderna. Trata-se, portanto, de pensar e analisar esses discursos por meio do papel e das funções que eles preenchem no interior do espaço social - discursos dotados de uma "lógica recorrente e metamórfica" (ANGENOT, 2008, p. 336). No entanto, meu propósito não é fazer a coleta, a coleção, nem a dissecação das mil e uma teorias da conspiração que abarrotam as novas mídias. As pistas que irei

\footnotetext{
${ }^{4}$ Pensemos, por exemplo, no uso que Alain Soral (polemista e ideológo de extrema direita, próximo de Dieudonné) faz do rótulo "dissidente" visando sua autopromoção, mas também no estatuto social e discursivo (aquilo que, em retórica, chamamos de ethos) do qual ele procura tirar proveito reivindicando-se como tal. Observemos particularmente a homepage do site desenvolvido por A. Soral, onde ele se apresenta como deportado, ostentando o triângulo vermelho (sobre o qual há um $\mathrm{F}$, de França) dos oponentes políticos. Acesso: http://www.egaliteetreconciliation.fr. Consultado em 11 de janeiro de 2016. Consideremos igualmente aquilo que M. Angenot (2014, p. 151) escreve a propósito da figura do ideólogo que, "da Idade Média aos tempos modernos", tenta se fazer perceber como "um 'puro"', um oponente, um excluído voluntário dos benefícios do sistema em vigor, tirando imensas vantagens pessoais de prestígio e glória devidas a sua posição doutrinária em meio aos “deserdados”.
} 
EID\&A - Revista Eletrônica de Estudos Integrados em Discurso e Argumentação, Ilhéus, n. 12, jul/dez.2016.

apresentar se propõem, de preferência, a ajudar a forjar instrumentos tanto para compreender essas produções do espírito quanto para responder a elas. Não obstante, cada um é livre para formar sua opinião conscientemente, livre para poder justificar e defender suas crenças por meio de palavras, livre para utilizar as ferramentas da retórica segundo suas convicções e seus valores.

\section{Uma questão de definição}

Para esquematizar, os termos complô e conspiração ${ }^{5}$ designam, um e outro, (a) uma ação acordada entre pelo menos duas pessoas, (b) preparada secretamente, em outros termos, escondida do olhar daqueles que não conspiram e, (c) buscando prejudicar, quer uma personagem pública ou uma instituição, quer, como geralmente é o caso nos dias de hoje, as maiorias, o povo, os cidadãos, as massas trabalhadoras, as pessoas honestas etc. As manobras postas em questão (d) são suspeitas, então, de desestabilizar uma certa ordem de coisas que se considera harmoniosa, criar desordem ou uma ruptura na continuidade das coisas, colocar em perigo aquilo que, até então, se considerava bem estabelecido, seguro e estável.

Consequentemente, compreendemos que, de uma forma ou de outra, toda descontinuidade, todo drama, todo desastre (uma guerra, uma epidemia, uma crise financeira, uma catástrofe ecológica, que mais poderia ser?) pode ser lido, retrospectivamente, como o resultado (possível) de um plano, de um acordo, de um desígnio secreto ligado a uma certa intenção e a certos homens que têm uma capacidade de prejudicar e um poder inversamente proporcional ao fato de serem poucos em número. Homens que não sabemos necessariamente quem são (se não conspiradores escondidos), mas que sabemos necessariamente que existem e agem em qualquer lugar. Melhor, quanto mais o acontecimento é sentido como injusto e doloroso, difícil de aceitar, incompreensível diante das formas comuns de compreensão do mundo, mais ele é suscetível de receber uma explicação do tipo conspiracionista, a qual se empenha, ainda que minimamente, para restaurar o sentido perdido e recolher os pedaços de uma experiência em frangalhos. Ela dá corpo, forma humana, às razões e às causas de uma desgraça qualquer, dá lugar à imaginação, convida a perpetuar a atualização de laços invisíveis que testemunham de fato que aquilo que se passou, o drama, o desastre, não ocorreu

\footnotetext{
${ }^{5} \mathrm{~A}$ fim de dispor de uma compreensão mais completa dos diferentes sentidos e empregos próprios aos dois termos, vamos nos referir às definições do Trésor de la langue française informatisé, disponível em: http://atilf.atilf.fr.
} 
EID\&A - Revista Eletrônica de Estudos Integrados em Discurso e Argumentação, Ilhéus, n. 12, jul/dez.2016.

sem razões, nem por nada. Inversamente, enquanto tudo vai bem, enquanto o mundo está "encantado", a explicação pelo complô tem dificuldade de ocorrer. De fato, não há necessidade de se assegurar, de se corroborar, nem de encontrar um sentido que, por definição, não falta a ninguém.

Muito concretamente, o enfoque conspiracionista funciona a partir do princípio de uma leitura, depois de uma narrativização totalizante e deteminista (B existe, porque A existe) de "sinais" coletados aqui e ali, na atualidade imediata como num passado mais ou menos distante, e isso com a intenção tanto de esclarecer o passado e o presente, como de predizer o futuro. Operando em todas as direções com vistas a produzir um conjunto explicativo coerente, maciço e seguro, ele se concentra em (1) recolher e combinar acontecimentos esparsos, elevando-os ao estatuto de fatos concretos, para (2) fazê-los atuar juntos no seio de uma trama narrativa; isso na intenção (3) de provar que esses fatos estão necessariamente ligados entre si (4), no sentido de que são o resultado de uma causa única, isto é, (5) de um complô em que os fatos falam por si e, (6) no seio do qual, os participantes respondem a uma natureza profunda, uma agenda escondida, obrigações ou pulsões maldosas e destrutivas (para a maioria, o povo, os "marginalizados"...) que os determinam.

Por exemplo, a ideia segundo a qual existe, ou existiria, "sinais que não iludem" é recuperada na entrevista dada ao jornalista suíço Darius Rochebin por Joseph Blatter, depois de sua reeleição, em 29 de maio de 2015, à frente da Federação Internacional de Futebol (FIFA), antes que viesse a se demitir, finalmente, três dias mais tarde. Blatter se atém a fornecer respostas às acusações de corrupção levantadas contra a FIFA e reage à prisão de sete de seus altos funcionários. Recusando-se a acreditar numa "simples coincidência" e se baseando, de um lado, numa confusão ("isso não cheira bem") e, por outro lado, numa interpretação de uma série de "sinais" (a agitação dos veículos de comunicação ingleses, a implicação dos Estados Unidos identificados como o primeiro apoiador da Jordânia, portanto, "de seu adversário"), Blatter invoca razões ocultas tanto por trás do "ataque americano" como por trás da "reação da UEFA (Liga Europeia de Futebol) do senhor Plantini". A leitura dessas razões - conduzida pelos verdadeiros lúcidos - é adequada para dar sentido à situação delicada e, para ele, inaceitável, na qual ele se encontra juntamente com outros. "Sinais" que não deixam de soar, por conseguinte, como provas tangíveis de que o complô está presente: 
EID\&A - Revista Eletrônica de Estudos Integrados em Discurso e Argumentação, Ilhéus, n. 12, jul/dez.2016.

Ninguém me dissuade da ideia de que é [mais que] uma simples coincidência este ataque americano dois dias antes das eleições para a FIFA e, em seguida, a reação da UEFA ou do senhor Plantini. [... ] Mas, enfim, isso não cheira bem. [... ] Há, como eu diria, sinais que não enganam: os americanos eram candidatos à Copa do Mundo de 2022, eles perderam. Os ingleses eram candidatos à Copa do mundo de 2018, eles perderam. Então [o problema surge] justamente com os veículos de comunicação ingleses e o movimento americano que vem agora se implantar na FIFA. [...] Há alguma coisa que não vai bem. [...] Não podemos esquecer que os Estados Unidos são o patrocinador número um do Reino da Jordânia, então, meu adversário ${ }^{6}$.

\section{Racional versus irracional: um impasse}

Embora seja agradável pensar o contrário para se tranquilizar, estamos todos inclinados, em graus diversos, a raciocinar na base de explicações do tipo conspiracionista, explicações que se apoiam sobre a existência de causas e ações escondidas (que podem ser atribuídas a qualquer pessoa ou a alguma pessoa em particular) que podem agir contra nós. Um fracasso escolar ou profissional, uma disputa de vizinhos, um conflito familiar, uma ruptura amorosa, e começamos a levantar hipóteses de cenários possíveis, complexos, tortuosos e até duvidosos para explicar este fato. Cenários que, bem frequentemente, nos ajudam a preservar a face, a conservar uma certa autoestima, a restaurar nosso orgulho ferido, fazendo repousar sobre o outro, os outros, a instituição, os dirigentes, o (bem famoso) "sistema" etc., a responsabilidade da situação dolorosa. É porque, mesmo que a vontade não falte, não saberíamos agir a partir de uma dicotomia tão rígida entre, de um lado, os homens racionais, os espíritos coerentes e lúcidos e, de outro, os crédulos, os ingênuos, os imbecis, os fantasiosos de todo tipo: aqueles para quem essas teorias fazem sentido de uma maneira ou de outra ${ }^{7}$. De resto, admitimos que a dicotomia, naturalmente reversível, é também válida a partir da outra posição: os crédulos (aos olhos dos primeiros) se proclamam esclarecidos e denunciam seus acusadores como ingênuos ou perversos incapazes de ver a verdade que se apresenta diante deles. $O$ impasse, então, é questão de se satifazer com uma análise no espelho inverso, seguindo aqueles "lúcidos" tomados como heróis por uns, respondendo aos "cegos" ridicularizados por outros.

\footnotetext{
${ }^{6} \mathrm{O}$ vídeo da entrevista pode ser consultado no site da internet da Radio Télévision suíça (RTS). Acesso em: http://www.rts.ch/play/tv/videos-en-bref/video/sepp-blatter-lentretien-integral?id=6824365\#\%2Ft=0. Consultado no dia 10 de janeiro de 2015.

${ }^{7}$ De resto, a partir de um grande número de estudos socilógicos, G. Bronner (2013, p. 282) afirma "que a formação intelectual dos espíritos não implica forçosamente uma proximidade com o pensamento científico e não imuniza contra as crenças falsas ou douvidosas". E o autor lembra que "certos personagens eminentes da história, consagrados por sua reputação intelectual, foram eles mesmo conhecidos por sua adesão (ao menos relativa) a crenças absurdas".
} 
EID\&A - Revista Eletrônica de Estudos Integrados em Discurso e Argumentação, Ilhéus, n. 12, jul/dez.2016.

Não tenhamos a estupidez nem a imprudência de acreditar que apenas os espíritos simples e ignorantes, as psicologias frágeis, são suscetíveis de cair na armadilha ilusionista das explicações conspiracionistas (NICOLAS, 2016). Pelo contrário, é necessário reconhecer a tendência ordinária que temos todos, aí compreendidos aqueles do campo científico, a descartar com desprezo ou a zombar das ideias e opiniões que, a priori, nos parecem "ininteligíveis" ou "absurdas". Tendência que nos leva muito facilmente "a concluir [...] que o grupo ou o indivíduo" que as sustenta está "investido de uma 'fé' destituída de razões":

\begin{abstract}
Uma crença coletiva, mesmo que julgada deplorável e odiosa, é sempre uma máquina a suscitar raciocínio e argumentações; descartá- las a priori não é bom método. [...] Os argumentos que sustentam uma crença, particularmente uma crença de que eu não gosto, vão ser sem dúvida julgados maus argumentos, comportando generalizações abusivas, non sequitur, contradições internas, paralogismos. [...] A ideia de que as crenças falsas [...] estão fundadas sobre outra coisa que não a razão, estão fundadas sobre "estados de alma" coletivos, sobre o irracional estabelecido, sobre "forças" sociais que se impuseram à consciência do indivíduo, é antes de tudo uma ideia intuitiva. De fato, nada se origina mais da intuição espontânea do que a tendência a rotular de "crença irracional", "ilusão", "necessidade inconsciente", "influência do meio", "condicionamento", as ideias que eu não compartilho; assim eu me livro impune da necessidade de compreender por que e em que medida elas tinham ou têm sentido e credibilidade, em outros espaços e para outros (ANGENOT, 2014, p. 115-116).
\end{abstract}

Marc Anegenot (2014, p. 119-121) segue sublinhando que as "boas razões" que os indivíduos formulam de maneira coletiva para dar sentido a uma situação dolorosa e restabelecer uma coerência perdida ou muito incerta, ainda que não representem "minimamente a Razão", refletem "um contexto 'vivido' que devemos buscar para que seja explicado ao mesmo tempo que os esclareceremos parcialmente". Além disso, Angenot (Ibid.) mostra que, "nas sociedades modernas", que são "polívocas, conflituais e compartimentadas, as boas razões de uns entram em conflito sincrônico com as, por vezes, melhores razões dos outros".

De fato, enxergar um complô (pequeno ou grande) por trás de um drama, um desastre vivenciado, não é irracional em si, notadamente quando se trata, num primeiro momento, de buscar apaziguamento e quietude construindo-lhe um sentido, recriando laços e causalidades, traçando os contornos de uma ordem de mundo justa. Estabelecido isso, eu não defendo que se trate da única resposta possível ao drama ou ao desastre em questão, nem que o sentido construído seja satisfatório, congruente em relação à realidade ou eticamente válido, somente que não há, no trabalho de construir coerentemente eventos esparsos, na 
EID\&A - Revista Eletrônica de Estudos Integrados em Discurso e Argumentação, Ilhéus, n. 12, jul/dez.2016.

narrativa que se manifesta, nada de absolutamente irracional. E ainda que falte mais de um passo para se chegar ao grande complô mundial (que incrimina, juntos ou separadamente, o governo americano, Israel, o grupo Bilderber, o Fundo Monetário Internacional, o Banco Mundial, a Organização Mundial do Comércio, a Comissão Trilateral etc.), a reviravolta do espírito permanece indubitavelmente a mesma: identificar as causas; controlar a explicação; singularizar-se; certificar-se do estabelecimento da possibilidade de um mundo justo. Considerando que a história é abundante em complôs sancionados por sucessos diversos (o assassinato de Júlio César, o Caso dos Venenos ${ }^{8}$, complô de 20 de julho de 1944 contra Hitler, Watergate etc.), devemos entender que não é proibido questionar, duvidar, pensar que complôs continuam sendo tramados ainda hoje em dia. Ademais, esta posição se encontra amplamente alimentada, reforçada pelo sentimento de corrupção dos políticos (nascido de suas mentiras, cartéis, conflitos de interesse, constatados ou presumidos) e pela desconfiança em relação aos grandes veículos de comunicação.

Pior, o ponto é capital, a modernidade erigiu a crítica e a dúvida como valores supremos. A modernidade fez da crítica e da dúvida o coração da autonomia do sujeito, o coração da razão moderna. Aquele que duvida, que expressa sua incredulidade, que busca criar sua própria opinião e saber mais, que não tem uma confiança cega na autoridade dos poderosos nem nas intenções daqueles que decidem, parece responder, em primeiro lugar, às exigências do espírito moderno. Ele se sente, mais do que qualquer outro, confortado e justificado na posição que adota e busca defender diante daqueles que recebem os acontecimentos do mundo e suas explicações sem interrogá-las. E ainda que isso venha, finalmente, para interferir no espírito e na prática daqueles que a exibem como um estandarte, a dúvida em questão consolida a convicão de ser o representante exemplar de uma razão que se encontra inatingível nos outros. As posições asumidas por Alain Soral ao longo de livros e monólogos intermináveis (difundidas por meio do site de seu movimento na internet "Égalité et Réconciliation" [Igualdade e Reconciliação]) se afiguram notáveis nesse ponto. Duvidar de tudo permite então não mais duvidar de tudo (DANBLON \& NICOLAS, 2010; NICOLAS, 2014).

\footnotetext{
${ }^{8}$ N.T.: O "Caso dos Venenos" é um episódio ocorrido em Paris entre 1670 e 1682, e que sacudiu a capital francesa e a Corte. Em 1672, com a morte do oficial de cavalaria, Godin de Sainte-Croix, descobrem-se em seus papéis peças acusando sua amante, Marquesa de Brinvilliers, de ter envenenado o próprio pai, seus dois irmãos e sua irmã, para apropriar-se de suas partes na herança. A Marquesa de Brinvilliers foi julgada e executada em 1676.
} 
EID\&A - Revista Eletrônica de Estudos Integrados em Discurso e Argumentação, Ilhéus, n. 12, jul/dez.2016.

Neste contexto, mesmo que as teorias da conspiração não tenham surgido ontem, nem mesmo anteontem, a modernidade - da qual tais teorias são os filhos rebeldes - Ihes deu uma dimensão singular e sem precedente, atribuindo alguma legitimidade àqueles que a sustentam, fazendo-as passar, aos olhos de alguns, por heróis e cantores da liberdade. Por sua vez, Pierre-André Tanguieff (2005) afirma que os anos 1990 - com a queda da União Soviética e os receios, à (extrema) esquerda como à (extrema) direita, diante do projeto de uma "Nova Ordem Mundial" (em inglês, "New World Order" ou Nwo), planejado por um governo oculto - e, depois, os anos 2000 - com os efeitos diversamente controlados da mundialização e dos últimos golpes dirigidos (entre outras vítimas) aos velhos mitos do progresso, do racionalismo e do universalismo viram o fenômeno conspiracionista se amplificar de modo considerável. Catastrofismo, lógica do pior e demistificação, de um lado, e busca do sentido oculto das coisas, caminhada em direção a uma totalidade perdida e aspiração ao reencantamento, de outro outro lado, vieram a constituir as duas faces de uma só e mesma política de suspeita generalizada.

\section{Efeito de evidência, argumentação e imunidade}

As explicações pelo complô, em outros termos, pela existência de razões ocultas, de laços subterrâneos, de forças ocultas, de pactos secretos, são particularmente eficazes pelo fato de que afirmam levantar o véu de uma realidade alegadamente dissimulada aos olhos de todos. Uma realidade perturbadora, inquietante e até terrível, que somente os mais corajosos, os corações puros, os cidadãos honestos são capazes de observar sem hesitação. O conhecimento desta realidade é então capaz de produzir um alívio inversamente proporcional ao terror que o incrível poder dos conspiradores pode, ou deveria, inspirar a todos. Por conseguinte, essas explicações deixam penetrar aqueles que a elas aderem (um pouco ou mesmo muito) num mundo do contra, um universo de iniciados admitidos a uma verdade profunda e proibida aos profanos, como, por exemplo: que as Torres gêmeas sofreram uma demolição controlada; que o vírus Ebola é uma invenção americana destinada a reduzir a população do continente negro; que o assassinato dos jornalistas de Charlie Hebdo é apenas uma operação sob "uma bandeira falsa" realizada pelos adversários do islã etc. Num vídeo disponibilizado em 11 de setembro de 2011, com o objetivo de fazer crer nas teorias conspiracionistas ligadas aos atentados cometidos dez anos antes, o cineasta Mathieu Kassovitz 
EID\&A - Revista Eletrônica de Estudos Integrados em Discurso e Argumentação, Ilhéus, n. 12, jul/dez.2016.

testemunha tal estado de espírito e conta seu trajeto pessoal: "Admitir que alguma coisa não segue a tese oficial, compreender a maneira pela qual ela evidentemente foi fabricada, [... ] é um trabalho sobre [si mesmo] que muitos não são capazes de fazer, que a maioria não é capaz de fazer"' . Quanto à realidade, considerada notória, dessa fabricação, evidentemente, não se permite a dúvida.

Em suma, a lucidez e o encontro da evidência não são concedidos a todos. A verdade se merece. Ela se obtém apenas com muita luta: pela frequência assídua aos "sinais que não enganam", pelo "trabalho sobre si mesmo", pela renúncia às "teses oficiais", pela recusa "heroica" das aparências ilusórias. Como o explica, de uma forma que, no mínimo, pode ser considerada tópica, um certo "Goldin" (num forum on line dedicado ao jogo de representação - role playing game - World of Warcraft), a propósito de uma pretensa conspiração mundial dos Illuminatis, a conversão à evidência implica um esforço pessoal de abrir os olhos, uma reaprendizagem da visão, uma fuga da cegueira geral: "Posso compreender que para algumas pessoas educadas na mentira desde o nascimento [...] é difícil crer nas teorias da conspiração, eu mesmo de início não acreditava nelas, foi preciso tempo para me convencer de que o mundo não é mais que um monte de mentiras" ${ }^{\prime 0}$. A partir de então, a evidência de todos, evidência dos cegos de algum tipo, se vê substituída pela evidência dos que veem, a única real e autêntica, a qual, cronologicamente posterior, não é menos primeira em valor e em verdade. Surgido de um afastamento voluntário do pretenso mundo das aparências, o efeito de evidência constitue, neste caso, um recurso maior das teorias do complô. De resto, esse efeito permite ao discurso conspiracionista funcionar isoladamente e em circuito muito fechado, servindo para refletir o mundo do contra sobre si mesmo, sobre a narrativa que, então, lhe dá corpo. Ele imuniza a explicação diante da crítica e da dúvida, e isenta aqueles que aderem ao ato de questionar mais profundamente e expor essa sua adesão à crítica. A isso, junta-se uma análise de Marc Angenot (2014, p. 230) sobre o que ele chama de "comunidades na base de persuasão", as quais se encarregam - escreve ele de poupar "a seus membros objeções que só poderiam vir 'do exterior' e que,

\footnotetext{
${ }^{9}$ Extraído da tribuna livre que circulou na internet por Mathieu Kassovitz em 11 de setembro de 2011: http://www.agoravox.tv/tribune-libre/article/mathieu-kassovitz-parle-du-11-31679. Consultado em 16 novembro de 2015.

10 Mensagem de "Goldin" postada em 20 de agosto de 2010. Acesso: http://kirintorrp.forumsrpg.net/t3461-illuminatis-franc-macon-et-le-complot-mondial. Consultada em 10 dezembro de 2015.
} 
EID\&A - Revista Eletrônica de Estudos Integrados em Discurso e Argumentação, Ilhéus, n. 12, jul/dez.2016.

para não mais escutá-las, o grupo encontra seus meios [...]. Elea Ihes poupam também os desmentidos que, por acaso, venham do mundo empírico, [e] Ihes proporcionam, enfim, meios de resistência obstinada e de surdez voluntária, e um arsenal de respostas sofisticadas destinadas a reconstruir suas certezas eventualmente abaladas.

Compreendamos bem, se a evidência está presente, isso quer dizer que não há, ou não há mais, necessidade de buscar argumentos para justificar aquilo que, por definição, não traz nenhuma dúvida: aquilo que ninguém sensato saberia contestar de boa fé. A esse respeito, sabemos, desde Aristóteles até Chaïm Perelman, que, quando se trata de fazer admitir ou promover uma tese cuja evidência deveria "se impor a todo espírito atento, não há espaço para argumentar: sempre que a verdade [se oferece] de maneira coercitiva, quando a evidência não deixa à vontade nenhuma liberdade de escolha, toda retórica é supérflua" (PERELMAN, 1982, p. 207). Consequentemente, a lógica específica dos discursos conspiracionistas não é a de argumentar (mesmo que os recursos argumentativos estejam disponíveis em camadas sobre camadas, como uma torta mil-folhas) nem dar razões para acreditar naquilo que se coloca realmente, mas a de apontar os lugares (supostos conhecimentos originados dos agentes do complô) onde nascem as ilusões, os desprezos, as mentiras; indicar o ponto em que a evidência, por definição, não poderia ser encontrada, os grandes veículos de comunicação; as "teses oficiais"; os discursos institucionais; a pesquisa subvencionada... Do "embuste da chegada do homem à lua" (HERMAN, 2010) às (falsas) execuções do Estado islâmico", os exemplos são numerosos. Em outros termos, a evidência, que nasce da recusa em aceitar o que é julgado muito evidente, protege a explicação conspiracionista contra as tentativas de subverter-lhe a legitimidade. Isso se deve menos ao que é dito a respeito dos fatos (sua interpretação, sua leitura) do que à exploração, e até mesmo à superexploração, da ambiguidade que não cessa de habitá-los.

Que o retrovisor do veículo utilizado pelos irmãos Kouachi durante o atentado de Charlie Hebdo seja cromado e possa parecer ora branco, ora

\footnotetext{
11 Podemos consultar o artigo "Exécutions de l'El: une mise en scène dévoilée, McCain éclaboussé" [Execuções do El: uma encenação desvelada, McCain manchado] publicado em 11 de julho de 2015 no site de informação pró-russo e conspiracionista Sputnik: "Lembremos que desde agosto de 2014, os terroristas do Estado islâmico publicaram inúmeros vídeos de execuções. Suas vítimas estavam contudo miraculosamente calmas, pronunciavam suas últimas palavras e morriam nos braços dos terroristas. Numerosos internautas consideraram esses vídeos fictícios, principalmente por causa das reações dos torturados e da qualidade dos vídeos". Acesso: http://fr.sputniknews.com/international/20150711/1016963919.html. Consultado em 6 de janeiro de 2016.
} 
EID\&A - Revista Eletrônica de Estudos Integrados em Discurso e Argumentação, Ilhéus, n. 12, jul/dez.2016.

preto, em função de sua exposição, não poderia, aos olhos dos crentes (para quem a existência de dois veículos não parecia, porém, levantar qualquer dúvida), desqualificar a tese do complô nem ameaçar a pertinência de sua abordagem $)^{12}$. Aqui, é o próprio "problema" que toma o lugar da evidência, logo de prova, que uma manipulação aconteceu. Em conformidade com o "efeito Fort"", descrito por Gérald Bronner (2013, p. 87-93), a confrontação com a realidade objetiva não se afigura manifestamente suficiente para desacreditar a tese do complô nem para comprometer sua eficácia persuasiva. De fato, potencialmente sem fim, a requalificação dos fatos sob o olhar e elementos novos permanece sempre possível. A partir daí, as requalificações sucessivas (que evitam denunciar a própria teoria, seus fundamentos, seus princípios) desenham o itinerário de um pensamento fechado e, em última análise, profundamente estéril (NICOLAS, 2010).

No espírito dos adeptos, o desmentido factual trazido a B (no caso, a presença de dois veículos) não poderia absolutamente ameaçar a existência de A, o complô enquanto tal. Assim, ainda que isso possa incomodar ou inquietar, no que tange aos riscos resultantes para a estabilidade de nossa relação com o mundo e a uma certa concepção de bom senso e da razão, é preciso admitir qua a passagem de não-B para não-A não é obrigatória, ao menos não totalmente. Além disso, querer explicar essa manobra em termos de "imunidade" diante da crítica e da apresentação de provas, perante a realidade dos fatos, é pertinente até certo ponto. Essa explicação ajuda a compreender a eficácia muito real do cordão de isolamento ou de segurança estabelecidas pelas "teorias do complô", para preservar a integrigade de sua visão de mundo segundo a qual o complô é a lei. A esse respeito, poderíamos utilizar a metáfora do telhado de vidro sobre o qual os fatos se esgotam ou expiram. Fatos que cada um pode ver, e que ninguém poderia absolutamente

\footnotetext{
${ }^{12}$ Os propósitos de alguém chamado "Jaxon" me parecem exemplares desse modo de raciocinar: "Graças a Panamza, ainda uma vez, você faz a diferença e traz glórias ao jornalismo de investigação. Por muito que custe a Mr. Barbier, com sua liberdade de expressão geometricamente variável, seu quadro de merda e sua écharpe. E certamente, quando Foures e seus mestres falarem da teoria do complô, tudo que eles serão capazer de citar serão os famosos retrovisores e a cabeça [do policial Ahmed] Merabet... Eles seriam perfeitamente incapazes de levantar todos os pontos pertinentes que você levanta a partir deste caso sombrio". Datadas de 1 de fevereiro de 2015, essas linhas comentam um artigo do site Panamza.com (site de informação considerada "subversiva" e notoriamente antissemita) publicado em 31 de janeiro de 2015: "Os terroristas de Charlie Hebdo mudaram de veículo diante de um local utilizado pela armada israelense”. Acesso: http://www.panamza.com/310115-charlie-israel-patistory. Consultado em 20 de novembro de 2015.

${ }^{13}$ NT: Esse chamado "efeito Fort" tem origem no nome de Charles Fort, autor de Le livre des damnés, que, de forma livre, pode ser traduzido como O livro dos malditos. Segundo Bronner, o "efeito Fort" consiste em acumular fatos e hipóteses como se fosse uma torta mil-folhas.
} 
EID\&A - Revista Eletrônica de Estudos Integrados em Discurso e Argumentação, Ilhéus, n. 12, jul/dez.2016.

ignorar: a transparência do telhado exige. A esse respeito, Joseph E. Uscinski \& Joseph M. Parent mostram, não sem uma pitada de humor e de malícia, que:

\begin{abstract}
Quando as predições de certas teorias do complô não se concretizam e nada é corroborado, elas merecem simplesmente desaparecer para sempre. As declarações de imunidade peculiares a essas teorias não deveriam lhes garantir vida eterna. As teorias do complô deveriam ser obrigadas a provar, num prazo razoável, o que elas apresentam ou, na falta disso, serem impiedosamente abandonadas. Há muito mais problemas urgentes no mundo para se ficar perdendo tempo com a matéria cinzenta de um impasse sem futuro (USCINSKI \& PARENT, 2014, p. 36, tradução minha) $)^{14}$.
\end{abstract}

Todavia, a explicação para a imunidade se afigura, eu creio, um pouco mais fácil e confortável. Ela mostra imediatamente os argumentos utilizados para conservar uma certa crença em $A$ a despeito da refutação de $B$ como irracionais, ou mesmo como patológicos. Certamente, o excesso de racionalidade - por meio do qual os "teóricos" do complô constroem suas provas, o seu lado eminentemente racionalizador - testemunha uma deriva da razão, a qual é então incapaz de se colocar à prova dos fatos e dos outros (NICOLAS, 2014; DANBLON \& NICOLAS, 2010; 2012). Mas essa deriva não é apanágio do conspiracionismo. Ela se encontra, por exemplo, na imunidade desenvolvida pelos teóricos neoclássicos diante das posições e proposições dos economistas considerados "heterodoxos", quer dizer, na incapacidade que têm os primeiros de revisar seu sistema de crença integrando as críticas provenientes dos segundos (FULLBROOK, 2005). Importa procurar ainda mais distante, afrontar o problema desconfortável do acaso e da tranparência no seio do pensamento moderno.

\title{
5. Recusa do acaso e transparência absoluta
}

Em todo caso, no seio das teorias do complô, para aqueles que as produzem e a elas aderem, o acaso não tem lugar (BRONNER, 2006). Ele figura como um intruso na medida em que tudo que acontece principalmente o pior - é considerado como o resultado de intenções e decisões puramente humanas, que, para criar ilusão e cegueira, algumas pessoas vestem as roupagens do acaso. As desgraças, problemas e crises que acometem as sociedades, aquelas que fazem sofrer os homens, as minorias, os marginalizados, os simples, são necessariamente imputadas àqueles "poderosos", alguns "grandes", que delas tiram proveito e/ou prazer de uma

${ }^{14} \mathrm{~A}$ esse respeito, ver também Donovan (2002; 2004; 2006). 
EID\&A - Revista Eletrônica de Estudos Integrados em Discurso e Argumentação, Ilhéus, n. 12, jul/dez.2016.

maneira ou de outra. Para aqueles que apoiam as explicações conpiracionistas, o mundo, povoado de sombras e de aparências, não é jamais como parece, jamais como "alguns" (tomado em sua extensão mais ampla) queriam nos fazer aceitar. Esses últimos atribuem aos atores sociais uma racionalidade todo-poderosa e uma confiaça a toda prova. Racionalidade que, muito simplesmente, não é encontrada porque não é humana. Joseph E. Uscinski \& Jospeh M. Parent (2014) enfatizam claramente este ponto:

Incontestavelmente, os indivíduos são às vezes racionais, mas os teóricos do complô postulam que os atores implicados em suas teorias sempre o são. [...] Há, por um lado, a racionalidade, por outro, há a hiper-racionalidade. Os teóricos do complô consideram sempre que os conpiradores têm a capacidade extralúcida de conhecer antes a maneira pela qual seus planos vão se desenvolver nas condições de volatilidade. [...] Aqueles que conspiram são frequentemente supostos de agir conforme o plano deles, e isso a todo momento ${ }^{15}$ (USCINSKI \& PARENT, 2014, p. 45, tradução minha).

De fato, se a "razão" (mesmo perversa; sobretudo, perversa) está aí, onipresente, onipotente, o acaso é excluído. Renunciar às sirenes das explicações pelo acaso é então sair da cegueira. Eis o que escreve um internauta, "Testou”, a propósito dos desdobramentos do atentado ao Charlie Hebdo: "Tipos muito bem preparados, com sangue frio a toda prova, profissionais. A fuga preparada [...]. Eles sabiam o que faziam. Não há acaso neste gênero de atentado". Algumas postagens abaixo, outro internauta, “Ryann”, comenta o seguinte: "Além disso, o veículo roubado foi abandonado no número 45 da rua de Meaux, no $19^{\circ}$ bairro de Paris, não distante da Michkenot Israel, sinagoga sob a autoridade do grande rabino de Paris, Michel Gugenheim. Talvez uma pista a explorar...?"16. Neste caso, as reticências estão carregadas de subentendidos.

Isso dito, esta mentalidade não é privilégio dos amadores de intrigas dados a perceber conspirações por toda parte. Ela reside, digamos, no próprio coração do desejo que temos de tornar as coisas controláveis, mensuráveis, calculáveis, bem asseguradas, no coração de nossa sede de eficácia e de certeza, em suma, no coração de nossa modernidade. Essa modernidade,

\footnotetext{
${ }^{15}$ Ao mesmo tempo, e é aí que reside uma parte da contradição, se é possível conhecer o complô é que, a despeito dessa racionalidade anormal, os conspiradores se encontram confrontados, a despeito deles mesmos, ao "caráter imprevisível da vida e das pessoas; [eles] devem [então] mudar seus planos, errar, e se veem obrigados a improvisar corrigindo-os apressadamente" (USCINSKI \& PARENT, 2014, p. 45, tradução minha).

16 Mensagens postadas em 7 e 8 de janeiro de 2015. Acesso: http://www.egaliteetreconciliation.fr/Fusillade-a-Charlie-Hebdo-au-moins-12-morts-dont-Charb-Cabu-etWolinski-30097.html. Consultado em 20 de dezembro de 2015.
} 
EID\&A - Revista Eletrônica de Estudos Integrados em Discurso e Argumentação, Ilhéus, n. 12, jul/dez.2016.

fascinada pelo que é puro, harmonioso, regrado e calibrado, transformou a estabilidade, a ordem, a previsibilidade dos seres e dos acontecimentos do mundo em um ideal da vida boa, um fundamento de nossa existência e de nossas expectativas políticas. Ela substituiu "o universo da precisão" pelo "mundo por aproximação" (KOYRÉ, 1948), que, até então, prevalecia. Partindo do princípio de que a exatidão é desse mundo (algo que os Antigos, por seu lado, jamais teriam admitido), a modernidade, então, consagrou o "acaso selvagem" como o outro mal radical, trabalhando sem descanso por sua erradicação.

Antigo operador de mercado que se tornou filósofo, Nassim Nicholas Taleb (2012, p. 136-138) identifica na modernidade um "polimento sistemático das irregularidades do mundo e a repressão da volatilidade e das pressões" do meio ambiente. Mais ainda, ele vê a coroação impressionante de uma "crença incondicional na predição científica em qualquer domínio que seja". Uma crença que ele liga a uma vontade "de comprimir o futuro por meio de reduções numéricas" (Ibidem). A esse respeito, aplicando-se a negá-lo, ou de preferência a excluir as irregularidades e escórias em questão, fazendo do acaso um tipo de inimigo público, desprezando o que ele apresenta em termos de aproximação prática, separando os homens de seu meio ambiente, a modernidade os fez bem frágeis. Fragilidade que se caracteriza por um crescimento considerável da necessidade de informações de todos os gêneros (que, para a maioria, permanecem não essenciais), por um gosto desmesurado pelo que é claro e sem manchas, por uma idealização da transparência. Aqui se aninham o mito do controle absoluto e em tempo real, da onisciência, da cultura naturalizada. Sob essa ótica, a opacidade não poderia ser vista como uma propriedade inerente ao mundo e às coisas. Ela é tão somente o fruto de uma falha de nosso conhecimento, o produto maligno de manipulações (urdidas na sombra) de alguns que procuram embaralhar as cartas às escondidas.

Aqui, o problema é duplo. De início, uma tal concepção das coisas ignora ou negligencia as implicações práticas do processo de decisão: o silêncio tanto quanto a preterição que ele implica, o fato de que tudo não pode ser "decidido pelo turbilhão, pela agitação barulhenta dos veículos de comunicação, na transparência assimilada à imediatez e urgência" (GOYET, 2009, p. 473). Em seguida, ela esquece que o mundo não é transparente, não tanto quanto poderíamos pensar ou gostaríamos de acreditar, a respeito, 
EID\&A - Revista Eletrônica de Estudos Integrados em Discurso e Argumentação, Ilhéus, n. 12, jul/dez.2016.

sobretudo, dos avanços de uma ciência que tem a reputação de todopoderosa. Nossa história está pontilhada de acontecimentos desconhecidos, surpreendentes, espantosos. Acontecimentos que, sem cessar, colocam em perigo nossos antigos esquemas de pensamento, de interpretação, de leitura. A falência quase instantânea do fundo de cobertura do Long Term Capital Management, em 1998, é dessa ordem de acontecimentos, os atentados de 11 de setembro de 2001 e as "primaveras árabes" de 2010-2013 também o são. Isso não quer dizer, longe disso, que não sejamos capazes de produzir narrativas (grandes ou pequenas) a posteriori para tornar inteligível aquilo que se passou a partir dos sinais de alerta, selecionando, aqui e ali, na história vivida, índices pertinentes, mostrando que tal ação teve tal efeito. Não obstante, esses sinais, esses índices, essas ações só podem ser julgados alertas, pertinentes, ou causas de qualquer coisa, porque sabemos o que aconteceu... entre uma infinidade de outros possíveis e também prováveis.

De fato, as narrativas em questão, que dão uma ilusão muito confortável de continuidade e de transparência aos acontecimentos, deixam pensar ingenuamente que o que ocorreu é apenas "o prolongamento determinista de nossa percepção do passado" (TALEB, 2007, p. 256). Trata-se assim de um viés cognitivo maior que funciona com os conspiracionistas, mas não unicamente com eles. A esse propósito, Nassim Nicholas Taleb afirma:

[...] há um ponto cego: quando pensamos no amanhã, não o concebemos em termos do que pensamos ontem ou anteontem. Essa falta de introspecção faz com que não cheguemos a tirar a lição da diferença entre nossas previsões passadas e seus resultados subsequentes. Quando pensamos no amanhã, nós o projetamos simplesmente como um outro ontem (Ibidem, p. 256-257).

Enfim, reconheçamos que é preciso coragem, audácia e, sobretudo, ferramentas, linguageiras principalmente, para enfrentar o acaso e o "poder do imprevisível", para aceitar e responder aos incidentes ocorridos dos "cisnes negros" ${ }^{17 " . ~ E s s e s ~ u ́ l t i m o s ~ c o n f u n d e m ~ n o s s o ~ e n t e n d i m e n t o ~ e ~}$ enfraquecem sem cessar nossa relação com a realidade, com os outros e com nós mesmos, porque nada nos acontecimentos de nossa história, nada nas experiências estocadas no interior de nossa memória individual e coletiva,

\footnotetext{
${ }^{17}$ A expressão, popularizada por Nassim Nicholas Taleb (2007), faz referência à descoberta de cisnes negros, na Austrália, no fim do século XVII, em uma época em que os europeus consideravam, erroneamente, que só poderiam existir, por definição, cisnes brancos. Descoberta que não deixou de preocupar consideravelmente os ditos europeus, obrigando-os a revisar amplamente sua concepção de mundo. Por extensão, um "cisne negro" designa um acontecimento altamente improvável, cuja ocorrência, forçosamente imprevisível, é portadora de consequências excepcionais impossíveis de antecipar e, portanto, de controlar.
} 
EID\&A - Revista Eletrônica de Estudos Integrados em Discurso e Argumentação, Ilhéus, n. 12, jul/dez.2016.

permite verdadeiramente antecipar a amplitude das consequências dramáticas que eles trazem. Eles nos confrontam com uma precariedade que, no mínimo, não é confortável: uma precariedade, fonte de frustração e de ressentimento que não é fácil de assumir, a menos que sejamos violentos ou que tenhamos as ferramentas adequadas. Com efeito, ela testemunha nossa ausência de onipotência (que uma certa concepção da ciência e da razão modernas querem nos fazer crer) e de incapacidade que temos tanto de controlar verdadeiramente, quanto de explicar os acontecimentos do mundo.

\section{Conclusão}

Finalmente, para bem compreender o atual estatuto das teorias do complô, precisamos abordar o estatuto dos mitos de ontem. Diante das escleroses do pensamento pronto, o filósofo Georges Gusdorf (1953, p. 276) nos convida a não rejeitar o mito "como uma ordem do irracional ou do arbitrário, [nem] como uma fonte de representações fraudulentas que abusam de nossa confiança". Superstições e representações às quais os modernos teriam, acreditamos frequentemente, tido o bom gosto e a sabedoria de renunciar. Pelo contrário, Georges Gusdorf percebe neles um meio de assumir a opacidade e a complexidade do real, de se reapropriar do mundo operando um desvio por meio do imaginário. Para ele, o mito, que possui ao mesmo tempo uma função mediadora e uma dimensão revigorante, conecta os homens ao seu ambiente mais do que ele os desvia ou os separa dele. Ele os ajuda a tomar consciência de si mesmos, recoloca-os na totalidade e confere ao mundo uma dimensão estritamente humana, encarnada, porque, "medida e não desmedida", a narrativa mítica visa a "tornar a vida possível. Ela dá às sociedades humanas seu equilíbrio e sua permissão de durar" (Ibidem, p. 24). Por conseguinte, não poderíamos tomar argumento nem suspeita quanto ao caráter não literal da relação entre o mundo e o mito, nem quanto à extravagância desse último, para acusá-lo, num único gesto, de ser irracional e, portanto, sem valor, ainda que alguns não se privem de fazê-lo, justificando sua denúncia, de forma bem fundamentada, em nome da ciência e da racionalidade. Em outros termos, a consciência mítica dos Antigos e a das sociedades primitivas não são da ordem do embuste nem na alienação. Tratase antes de uma "muleta" ou de um apoio circunstancial a uma situação delicada, de um meio de passar pela prova do sentido (do não sentido, principalmente) ou de se recuperar depois dela. 
Concretamente, glorificando a ciência ou, ao menos, uma certa ideia da ciência, erigindo-a como única via da experiência e única medida da realidade humana, dando livre curso a uma verdade vencedora, por toda parte e sempre, a razão moderna descartou o mito e suas funções profundas. Ela debilitou duradouramente suas condições de exercício ritualizado. Ela lhe retirou sua dimensão prática, precisamente humana. Com o objetivo de estabelecer o espírito por si mesmo, espírito sem corpo, quer dizer igualmente sem instintos, o positivismo e o intelectualismo desenfreados se esforçaram para matar o mito, expulsá-lo para fora da cidade, fora do mundo dos homens, fora da caixa de ferramentas de que eles poderiam dispor para habitá-lo e para dizê-lo. De fato, se o empreendimento de "desmistificação" permitiu descartar, sem dúvida justificadamente, as antigas "fabulações imaginativas", ele também provocou "a rejeição da afetividade [e uma] desconfiança sistemática diante do sensível". Assim, diante de uma consciência mítica decadente, nossa modernidade não prestou atenção ao "retorno do recalcado" (Ibidem, p. 198200). E, sem prestar atenção às consequências funestas que isso poderia ter, deixou seu avatar moderno se instalar, o qual, "liberado de todo controle tradicional, se revelou capaz de todos os excessos e de todos os horrores" (Ibidem, p. 213). Separando os laços ainda que estreitos entre "a razão" e os "instintos, que ele prolonga promovendo-os", o racionalismo que acalentamos está "condenado a ser irracional" (Ibidem, p. 312).

Enquanto o mito à moda antiga era realmente vivido, encarnado, reconhecido e aceito como mito, quer dizer, como uma "muleta", os mitos de hoje, estéreis e impraticáveis, são tomados por aquilo que eles não são, uma manifestação autêntica da ciência vitoriosa. Pior, eles tiram dessa reivindicação uma estatura e uma credibilidade inesperada. As teorias do complô, como as estudou Raoul Girardet (1986) ${ }^{18}$, ocupam o lugar de mitos políticos modernos. E isso no sentido de que a política se distanciou pouco a pouco de uma prática viva da palavra retórica, entendida como ferramenta para avançar num mundo fluido onde o precário é a lei: uma ferramenta para praticar e para colocar à prova sem cessar o campo dos valores. Essas teorias testemunham então um "tipo de alienação" no interior do qual "os valores fundamentais se encontram esterilizados ou ao menos anestesiados" (GUSDORF, 1953, p. 212-213). Por menosprezar o sensível e falhar no reconhecimento da opacidade do sentido, nós, modernos, vimos a crer em nossos mitos, a não ver neles ferramentas ou

${ }^{18}$ Ver também Dard (1998). 
EID\&A - Revista Eletrônica de Estudos Integrados em Discurso e Argumentação, Ilhéus, n. 12, jul/dez.2016.

instrumentos para habitar o mundo, mas um reflexo de sua realidade objetiva, uma simples e sadia apresentação dos fatos.

A esse respeito, Nassim Nicholas Taleb (2012, p. 260-263) faz uma distinção fecunda entre narração "instrumental" (que é um apoio da ação) e "epistemológica" (que funciona como uma armadilha no interior de uma teoria tomada ao pé da letra). A primeira é característica do mito à moda antida. Plebiscitada pela modernidade, a segunda habita, mas sem nenhuma exclusividade, as teorias do complô. Elas testemunham com força "nossa quase incapacidade de observar as sequências de acontecimentos sem lhes atribuir uma explicação, ou, o que é praticamente o mesmo, sem lhes atribuir a qualquer custo um liame lógico, uma flexa de relação". Como resultado, assim que "nossa impressão de compreender as coisas" se torna totalizante e tirânica, assim que a narrativa produzida sobre o mundo e os outros nos levam a considerar o futuro com os preconceitos do passado, assim que nos recusamos a reconhecer a opacidade da realidade, nós nos tornamos extremamente vulneráveis diante da "incerteza selvagem" (TALEB, 2007, p. 101). Ora, na falta de uma resposta alternativa, de uma consciência de suas causas, de lucidez sobre nós mesmos e sobre as explicações que fabricamos com os meios à nossa disposição, é esta vulnerabilidade que, sem cessar, reforça o lugar e o sucesso da abordagem conspiracionista. Vulnerabilidade que se torna inaceitável e que recusamos a assumir emprestando-lhe uma via humanista (NUSSBAUM, 2010, p. 39-62).

Então, uma questão se impõe, ela é crucial e repleta de implicações: é necessária uma maior influência das ciências e de suas certezas vitoriosas, ou uma maior prática da argumentação e uma melhor transmissão (no espaço escolar) das ferramentas retóricas suscetíveis de modificar em profundidade nossa relação com a narrativa e com o discurso em geral? Reconheçamos (sem, no entanto, dever ceder de forma alguma às sirenes do pós-modernismo) que, muito frequentemente, quando uma certa concepção - dogmática, se entenda da ciência passa, a retórica transpassa (NICOLAS, 2015b). Enquanto não tivermos reencontrado a via integradora de narrativas comuns e aquela do discurso retórico para "reencantar o perigo" (BRONNER, 2014), as teorias do complô disporão de campo livre para prosperar sem que nos seja possível nos defendermos delas, a não ser pela força do direito e pela violência política. 
EID\&A - Revista Eletrônica de Estudos Integrados em Discurso e Argumentação, llhéus, n. 12, jul/dez.2016.

\section{Referências}

ANGENOT, Marc. Dialogues de sourds. Traité de rhétorique antilogique. Paris: Éd. Mille et Une Nuits, 2008.

. L'Histoire des idées. Problématiques, objets, concepts, méthodes, enjeux, débats. Liège: Presses universitaires de Liège, 2014.

ARISTOTE. Rhétorique. Trad. do grego de M. Dufour (com A. Wartelle para o livre 3). Paris: Éd. Les Belles Lettres, 1931-1973.

BRONNER, Gérald. L'Empire des croyances. Paris: Presses Universitaires de France, 2003.

. Vie et mort des croyances collectives. Paris: Hermann, 2006.

. La Pensée extrême. Comment des hommes ordinaires deviennent des fanatiques. Paris: Denoël, 2009.

. La Démocratie des crédules. Paris: Presses universitaires de France, 2013.

. La Planète des hommes. Réenchanter le risque. Paris: Presses universitaires de France, 2014.

CREPON, Marc. La Culture de la peur. I. Démocratie, identité, sécurité. Paris: Galilée, 2008.

DANBLON, Emmanuelle; NICOLAS, Loïc (Dir.). Les Rhétoriques de la conspiration. Paris: CNRS Éd., 2010.

. Rhétorique et topique de la conspiration. Raison publique, n. 16, p. 33-42, 2012.

DARD, Olivier. La Synarchie. Le mythe du complot permanent. Paris: Perrin, 1998.

DONOVAN, Pamela. Crime legends in a new medium: fact, fiction and loss of authority. Theoretical Criminology, n. 6, v. 2, p. 189-215, 2002.

. No Way of knowing. Crime, urban legends, and the internet. New York: Routledge, 2004. 106, 2006

. Vaines paroles? Un siècle de recherche sur la rumeur. Diogène, n. 213, p. 74-

FULLBROOK, Edward. De la domination néo-classique et des moyens d'en sortir. L’Économie politique, n. 28, v. 4, p. 78-91, 2005.

GIRARDET, Raoul. Mythes et mythologies politiques. Paris: Éd. Le Seuil, 1986. 
EID\&A - Revista Eletrônica de Estudos Integrados em Discurso e Argumentação, Ilhéus, n. 12, jul/dez.2016.

GOYET, Francis. Les Audaces de la prudence. Littérature et politique aux XVI ${ }^{\mathrm{e}}$ et $\mathrm{XVII} \mathrm{e}^{\mathrm{e}}$ siècles. Paris: Classiques Garnier, 2009.

GUSDORF, Georges. Mythe et métaphysique. Introduction à la philosophie. Paris: CNRS Éd., 2012 [1953].

HAARSCHER, Guy. Diffamation collective: une notion irrémédiablement confuse?. Revue de droit de l'Université libre de Bruxelles, Bruxelas, v. 35, p. 51-73, 2007.

HERMAN, Thierry. L'irrésistible rhétorique de la conspiration: le cas de l'imposture de la lune. In: DANBLON, Emmanuelle; NICOLAS, Loïc (Dir.). Les Rhétoriques de la conspiration. Paris: CNRS Éd., 2010. p. 217-236.

HUGHES, Robert. The Culture of complaint. The fraying of America. Oxford: Oxford University Press, 1993.

KILPATRICK, William Heard. Philosophy of education. New York: Macmillan, 1951.

KOYRÉ, Alexandre. Du monde de l'à peu près à l'univers de la précision. Critique, n. 28, tome IV, p. 806-823, 1948.

NICOLAS, Loïc. Rhétorique du complot: la persuasion à l'épreuve d'elle-même. Itinéraire d'une pensée fermée. In: DANBLON, Emmanuelle; NICOLAS, Loïc (Dir.). Les Rhétoriques de la conspiration. Paris: CNRS Éd., 2010. p. 73-96.

NICOLAS, Loïc. L'évidence du complot: un défi à l'argumentation. Douter de tout pour ne plus douter du tout. Argumentation et analyse du discours, Tel-Aviv, n. 12, 2014. Disponível em: http://aad.revues.org/1833.

. Charlie Hebdo ou la société malade de son verbe. La Cité, ano 4, n. 4, p. 22-23, $2015 a$.

. Discours et liberté. Contribution à l'histoire politique de la rhétorique. Paris: Classiques Garnier, 2015b.

. Jésuites, juifs, francs-maçons: la rhétorique au service de la conspiration. Diogène, n. 249-250, p. 75-87, 2015c. Disponível em: https://www.cairn.info/revuediogene-2015-1-page-75.htm.

. Répondre au conspirationnisme. Erreurs, errances, remèdes. Revue des deux mondes, n. jul/ago, p. 88-97, jul/ago.2016.

NUSSBAUM, Martha. Les Émotions démocratiques. Comment former le citoyen du XXI ${ }^{e}$ siècle? Trad. do inglês de S. Chavel. Paris: Éd. des Climats, 2011 [2010].

PERELMAN, Chaïm. Droit et rhétorique. [1982]. In: LEMPEREUR, Alain (Dir.). L'Homme et la rhétorique. L'École de Bruxelles. Paris: Klincksieck, 1990. p. 207-212. 
EID\&A - Revista Eletrônica de Estudos Integrados em Discurso e Argumentação, Ilhéus, n. 12, jul/dez.2016.

PERELMAN, Chaïm; OLBRECHTS-TYTECA, Lucie. Traité de l'argumentation. La nouvelle rhétorique. Bruxelles, Éd. de l'Université de Bruxelles, 1988 [1958].

TAGUIEFF, Pierre-André. La Foire aux illuminés. Ésotérisme, théorie du complot, extrémisme. Paris: Éd. Mille et Une Nuits, 2005.

TALEB, Nassim Nicholas Le Cygne noir. La Puissance de l'imprévisible. Trad. do inglês de C. Rimoldy com colaboração do autor. Paris: Éd. Les Belles Lettres, 2012 [2007].

. Antifragile. Les Bienfaits du désordre. Trad. do inglês de C. Rimoldy com colaboração do autor. Paris: Éd. Les Belles Lettres, 2013 [2012].

USCINSKI, Joseph E.; PARENT, Joseph M. American conspiracy theories. Oxford: Oxford University Press, 2014.

Tradução:

Maria Helena Cruz Pistori

Doutora em Letras pela Universidade de São Paulo

Revisão da tradução:

Eduardo Lopes Piris

Docente da Universidade Estadual de Santa Cruz

Forma de citação sugerida:

NICOLAS, Loïc. As teorias da conspiração como espelho do século: entre a retórica, a sociologia e a história das ideias. Trad. Maria Helena Cruz Pistori. Rev. trad Eduardo Lopes Piris. EID\&A - Revista Eletrônica de Estudos Integrados em Discurso e Argumentação, Ilhéus, n. 12, p. 255-279, jul/dez.2016.

Recebido em: 02/06/2016

Aprovado em: 30/06/2016 